\title{
Differences between success factors of IS quasi-outsourcing and conventional outsourcing collaboration: a case study of two Finnish companies
}

\author{
Karin Väyrynen \& Marianne Kinnula \\ University of Oulu, Finland
}

\begin{abstract}
Conventional IS outsourcing does not always meet expectations, often because the company lacks control over the outsourced activity. Quasi-outsourcing collaboration, where the company transfers its IS personnel to a subsidiary, allows the company to maintain more control over the relationship than in conventional outsourcing. In this qualitative case study of two Finnish companies, differences between success factors of IS quasi-outsourcing and conventional outsourcing are identified and discussed. The study has practical and theoretical implications. We identified 1) success factors of conventional outsourcing that are already fulfilled (e.g. trust) or less challenging (e.g. physical information technology infrastructure) in quasi-outsourcing, 2) success factors that are more challenging in quasi-outsourcing than in conventional outsourcing (e.g. structured interaction processes), and 3) success factors that proved important in both types of outsourcing but showed qualitative differences (e.g. mutual dependency). Our findings can help companies make a more informed choice between these two types of outsourcing.
\end{abstract}

Keywords. Information systems, Outsourcing types, Qualitative research, Quasi-outsourcing

\section{Introduction}

Outsourcing has often been named a very important company business strategy in the New Economy era. Information system (IS) outsourcing can be classified into two typical but different patterns: conventional outsourcing and quasi-outsourcing (Matsuno et al. 2009). In conventional outsourcing, the company enters a contract-based relationship with an external service provider without having ownership of the provider. This form of collaboration has been researched widely (Lacity et al. 2009). Quasi-outsourcing, in contrast, is defined as the situation where the company creates a subsidiary and transfers certain business functions to it, keeping total or partial ownership of the new, independently managed company (Barthélemy and Geyer 2001,2005; Dibbern et al. 2004). Significant risks are related to outsourcing (Aubert et al. 2005; Bahli and Rivard 2005), and outsourcing outcomes are not always successful; one reason is that, in conventional outsourcing, the company loses control over the outsourced activity (Barthélemy2003). Quasi-outsourcing allows the parent company to retain control over the outsourced activities, even though the quasi-outsourced IS department behaves like an external service provider to the parent company (Barthélemy and Geyer 2001). According to Barthélemy and Geyer (2005), "quasi-outsourcing is a hybrid structure or governance that lies between market and hierarchy" (Williamson 1985), where the degree of market coordination increases when the parent's ownership of the service provider decreases (Matsuno et al. 2009). Therefore, quasi-outsourcing is away to balance market and organizational transaction costs (Barthélemy and Geyer 2005) and thus seems to represent a good alternative to conventional outsourcing. In a survey of 99 German companies, for example, $46.5 \%$ were found to use quasioutsourcing instead of conventional outsourcing (Barthélemy and Geyer 2001). Similar types of 
collaboration have been successfully used in Japan (Ito 1995; Matsuno et al. 2009). Even though a normal practice in industry (Barthélemy and Geyer 2005), quasi-outsourcing collaboration has hardly been the focus of IS outsourcing research. Studying what makes a relationship successful is one way of studying inter-organizational collaboration (Romano et al. 2010). Even though quasi-outsourcing represents a common alternative to conventional outsourcing, success factors of IS quasi-outsourcing, and whether and how they differ from success factors of conventional IS outsourcing, have not been studied yet. Our study seeks to close this research gap by comparing the success factors identified in a case where a Finnish internationally operating corporate group (case company "Alpha") quasioutsourced its software development, maintenance, and support activities, keeping full ownership of the quasi-outsourced company, to success factors of conventional outsourcing identified in previous research and a Finnish conventional outsourcing case (case company "Gamma"). The analysis presented in this paper complements and builds on the analysis and findings of an earlier study where success factors for the Alpha quasi-outsourcing case were identified (Väyrynen and Kinnula 2011). Our research has theoretical and practical implications, adding to previous research by identifying substantial differences between success factors for conventional and quasi-outsourcing. Our findings have practical relevance in raising companies' awareness of differences between conventional IS and quasi-outsourcing collaboration, helping companies to make an informed choice between these two outsourcing types.

Next, we present success factors of conventional outsourcing identified in previous research, and introduce the research setting and methodology. Following that, the results are presented and discussed. The paper concludes by summarizing theoretical and practical implications, research limitations, and suggestions for future research.

\section{Success factors of IS outsourcing collaboration}

Answers to the question "What makes an outsourcing relationship between two companies successful?" have come in different formats. Researchers have tried to find the answers by posing other questions such as, "What does relationship success mean?" (Grover et al. 1996; Lee and Kim 1999; Sabherwal 1999), "What are the reasons for getting involved in an outsourcing relationship?" (Baldwin et al. 2001; DiRomualdo and Gurbaxani 1998; Smith and McKeen 2004), "What were the factors that caused relationships to fail?" (Aubert et al. 1999; Lacity et al. 1994), "What are the risks of outsourcing and how to mitigate them?" (Bahli and Rivard 2005; Currie and Willcocks 1998; Earl 1996), or "What kind of a process leads into a successful relationship?" (Lacity et al. 1996; Venkatraman 1997). The results have been rather unified, and it seems that most successful collaborative relationships are based on immaterial factors such as trust between the parties and communication, as well as material factors, such as good contracts and personnel.

As relationship success is tightly tied to the realization of risks, some researchers have seen certain factors as risks in collaboration, while others have listed the same as the success factors of the relationship. To better understand what determinants influence collaboration success, we combined the most common risk and success factors presented in IS outsourcing literature (both presented in Lacity et al. 2009), and classified them as displayed in Table 1 (ordered alphabetically).

Understanding what factors generally affect the success of the collaboration is of course important. However, the success factors in a certain relationship are highly dependent on what is expected as the outcome of the relationship. Thus, following Anthony et al.'s (1972) emphasis on the need to tailor management control systems to companies' particular strategic objectives, we define successful outsourcing to be the situation where the objectives and expectations set for outsourcing are met. 
Table 1 Success factors of IS outsourcing collaboration

\begin{tabular}{|c|c|}
\hline Success factor & Source \\
\hline $\begin{array}{l}\text { Contractual governance: } \\
\text { detailed but flexible contract, short duration of contract and higher contract size } \\
\text { positively affect the outcome of the relationship } \\
\text { the customer retains control over the service provider }\end{array}$ & $\begin{array}{l}\text { Lacity et al. (2009) } \\
\text { Kern and Willcocks (2002) }\end{array}$ \\
\hline Cultural fit, i.e. fit in organizational cultures & DiRomualdo and Gurbaxani (1998) \\
\hline Mutual dependency between parties & Currie and Willcocks (1998) \\
\hline $\begin{array}{l}\text { Establishment of norms in the relationship (including flexibility, information } \\
\text { exchange and solidarity) }\end{array}$ & Kern and Blois (2002) \\
\hline Open sharing of information & Lee and Kim (1999) \\
\hline $\begin{array}{l}\text { Quality of service: } \\
\text { capability, skills and attitude of the service provider } \\
\text { honoring the IP rights, and security and privacy issues }\end{array}$ & $\begin{array}{l}\text { DiRomualdo and Gurbaxani (1998) } \\
\text { Currie et al. (2008) }\end{array}$ \\
\hline $\begin{array}{l}\text { Relationship management process: } \\
\text { communication and information sharing } \\
\text { cooperation processes } \\
\text { acquainting the customer's own employees with the new relationship to prevent } \\
\text { any backlash } \\
\text { outsourcing management }\end{array}$ & $\begin{array}{l}\text { Lee and Kim (1999) } \\
\text { Grover et al. (1996) } \\
\text { Bandyopadhyay and Pathak (2007) } \\
\text { Bharadwaj et al. (2010) }\end{array}$ \\
\hline $\begin{array}{l}\text { Retention of control over outsourcing, e.g. autonomy and control over information } \\
\text { technology (IT) decisions, control over data }\end{array}$ & Currie and Willcocks (1998) \\
\hline $\begin{array}{l}\text { Retention of core competences - taking care that essential skills and key persons } \\
\text { are not outsourced }\end{array}$ & Baldwin et al. (2001); Earl (1996) \\
\hline $\begin{array}{l}\text { Selective outsourcing - how big amount of IS budget or number of IS functions is } \\
\text { outsourced }\end{array}$ & $\begin{array}{l}\text { Lacity and Willcocks (1998); Bharadwaj et } \\
\text { al. (2010) }\end{array}$ \\
\hline $\begin{array}{l}\text { Careful service provider evaluation process: } \\
\text { in general } \\
\text { service provider financial stability }\end{array}$ & $\begin{array}{l}\text { Lacity and Willcocks (1998) } \\
\text { Earl (1996) }\end{array}$ \\
\hline Top management commitment and support throughout the process & Smith and McKeen (2004) \\
\hline Trust & $\begin{array}{l}\text { Kern and Willcocks (2000); Lee and Kim } \\
\text { (1999); Sabherwal (1999) }\end{array}$ \\
\hline $\begin{array}{l}\text { Understanding and managing all costs related to the outsourcing relationship, e.g. } \\
\text { transaction costs, hidden management costs, switching costs to another service } \\
\text { provider, possible cost savings, control of contract growth }\end{array}$ & $\begin{array}{l}\text { Aubert et al. (2005); Ho et al. (2003); Kern } \\
\text { and Willcocks (2000) }\end{array}$ \\
\hline Values, e.g. treating IT as an undifferentiated commodity & Willcocks and Kern (1998) \\
\hline
\end{tabular}

\section{Research setting and methodology}

The present study is based on data collected during two research projects conducted on industrial companies' software business activities. Previous research has presented success factors of conventional outsourcing often in the form of lists rather than offering qualitative description of the data. Therefore, instead of simply comparing the success factors of quasi-outsourcing to those identified by previous research in the context of conventional IS outsourcing, we wanted to compare them to the qualitative data of a conventional outsourcing case. This allowed us to gain insights into differences between conventional outsourcing and quasi-outsourcing that would not have been possible without the conventional outsourcing case's qualitative data.

As outsourcing success has to be evaluated in relation to the objectives and expectations set for outsourcing, we studied two outsourcing cases where the customer companies chose different types of outsourcing to achieve similar objectives. The Alpha-Beta collaboration case represented quasioutsourcing and the Gamma-Delta collaboration case conventional outsourcing. Outsourcing studies are often conducted either from the customer's or the service provider's point of view. In order to get richer understanding of the phenomenon, we collected data from both parties of the collaboration. 


\section{Case settings}

In quasi-outsourcing between Alpha, a Finnish internationally operating corporate group, and Beta, its subsidiary established in 2000, we focused on their collaboration from 2006 to 2009. From the 1980 s to 2006, development, support, and maintenance of the company's internal software applications and systems were handled mostly within a limited number of operational departments inside Alpha. In 2006, Alpha moved most of its operational departments' software developers-30 persons, mainly from Alpha's IS department and one of Alpha's operational departments - to Beta. Beta was legally an independent software company but offered its software development, maintenance, and support services almost exclusively to Alpha. Alpha fully owned Beta, but Beta was empowered to behave like an external vendor. Therefore, this case represents quasi-outsourcing where the parent kept full ownership of the quasi-outsourced company (cf. Matsuno et al. 2009).

In the conventional outsourcing case, Gamma, the customer company, is a large Finnish internationally operating corporation with a strong emphasis on software research and development. Delta, the service provider, is a Finnish IS services company focusing on vertical markets in different industries, providing typically either customer partnerships or repeatable solutions. Gamma outsourced a large amount of its core software R\&D work, and transferred laboratories and 318 of its employees, to Delta. The case was followed from 2000 to 2003.

\section{Data collection and analysis}

Data was primarily collected by conducting in-depth interviews. We interviewed six persons in eleven interviews at Alpha and Beta, and 30 persons in as many interviews at Gamma and Delta. In order to gain rich insights from the service provider's (Beta, Delta) and the customer's (Alpha, Gamma) perspectives, we interviewed persons from a number of different organizational positions, including managers in Alpha, Beta, Gamma, and Delta, personnel transferred from Alpha to Beta and Gamma to Delta, and personnel remaining in the customer organizations. Interview topics in both cases included the objectives of (quasi-)outsourcing, changes in capabilities and collaboration processes necessary in both the service provider and customer companies, and difficulties and success factors in implementing these changes.

The data was analyzed using processual analysis (Pettigrew 1997). We followed Eisenhardt's (1989) six steps for building theory from case study research. All interviews were audio recorded, and almost all transcribed after the interview. Already conducted interviews were briefly analyzed before additional interviews were conducted, to identify new factors that arose during an interview and would need further investigation (Step 1: overlap of data analysis with data collection). In Step 2 (analyzing within-case data), each interview transcript was coded, using the success factors of conventional outsourcing identified in previous research (see Table 1) as pre-codes, and both cases were analyzed independently for new success factors that proved important for achieving the objectives set by Alpha and Gamma. In Step 3 (verification of data description), interview reports were written up and sent to the interviewees for verification and to ensure construct validity (see Yin 2003). In Step 4 (searching for cross-case patterns), cross-case analysis was carried out by comparing the success factors of quasi-outsourcing and conventional outsourcing to identify differences. In Step 5 (shaping hypothesis), we arrived at our distinction between success factors that proved to be either less or more challenging in quasi-outsourcing than conventional outsourcing, and success factors that proved to be important in both types of outsourcing but showed qualitative differences between the outsourcing types. In Step 6 (enfolding literature), we compared our results to findings of previous research. 


\section{Reliability and validity tactics}

Validity and reliability have to be considered in qualitative research (e.g. Golafshani 2003). The present study follows the validity and reliability tactics for case studies as discussed by Yin (2003), who argues that four tests are commonly used in judging the quality of empirical qualitative research: construct validity, internal validity, external validity, and reliability.

In the study at hand, construct validity has been addressed by establishing a chain of evidence, and by asking the interviewees to review the description of the cases and to point out mistakes and misinterpretations. Internal validity has been addressed by explanation-building and pattern matching (by matching the empirical data of the present research with the success factors of conventional outsourcing identified in previous research), as well as by providing rich description in the discussion section of this study. In the present study, we generalize from empirical statements to theory (see Lee and Baskerville 2003), and our findings can thus be generalized within the case setting. Extending this study to a number of additional case settings would not increase its generalizability beyond these additional cases (see Lee and Baskerville 2003). However, conducting this study using replication logic (see Yin 2003) in other settings of conventional outsourcing and quasi-outsourcing cases would strengthen the external validity of our study. Finally, reliability has been aimed at by keeping research diaries over the whole period of the research process.

\section{Discussion of results}

In this section, we discuss the differences in success factors for quasi-outsourcing and conventional outsourcing based on the two outsourcing cases presented above. Some of the success factors proved to be more challenging in one type of outsourcing, and some of the factors have qualitative differences between outsourcing types. We also found success factors in which there were no considerable differences between quasi-outsourcing and conventional outsourcing (open sharing of information, quality of service, top management commitment and support, and understanding and managing all costs from management's viewpoint), and thus they are left out of this discussion. For some of the success factors listed in Table 1 (norms, relationship management process, and values), not enough data was available for comparison; therefore, those factors are not discussed in this study. In order to provide a more complete picture of similarities and differences between success factors of conventional outsourcing and quasi-outsourcing, Table 2 at the end of the Discussion of results section provides a summary of the success factors identified in previous research and the present research. We present below the objectives the companies pursued with outsourcing, as the success factors identified depend on the company's original goals for outsourcing. Next, we present success factors that proved to be either less or more challenging in quasi-outsourcing than conventional outsourcing collaboration. Finally, we present success factors that proved important in both cases, but that differed in how they were important in the two types of outsourcing. We present the citations from our empirical data in several figures to help the reader verify our findings. A code consisting of a capital letter for the company ("A" for Alpha, "B" for Beta, "G" for Gamma, "D" for Delta) and a number is designated for each citation (e.g. A1). This code is also used in the textual description of our findings to clearly link it to the citations.

\section{Objectives pursued with outsourcing collaboration}

Alpha and Gamma pursued some very similar objectives with (quasi-) outsourcing. First, both companies wanted to reduce costs by using different means, i.e. by reducing fixed costs [G1, G2, B1], by improving cost efficiency [G1, G3, A1], and by exploiting economies of scale [A2]. Second, both companies wanted to increase flexibility in using their software and R\&D resources $[G 6, D 1, A 3$, 
A4]. In addition, Alpha wanted to improve the software development process [B2], and Gamma wanted its own personnel to concentrate on core activities while Delta would handle the non-core activities as well as the more trivial parts of the core activities [G4, G5]. All of these objectives are among the most common strategic intents for IS outsourcing mentioned in the literature (Lacity et al. 2009).

Figure 1 summarizes the objectives pursued with conventional and quasi-outsourcing.

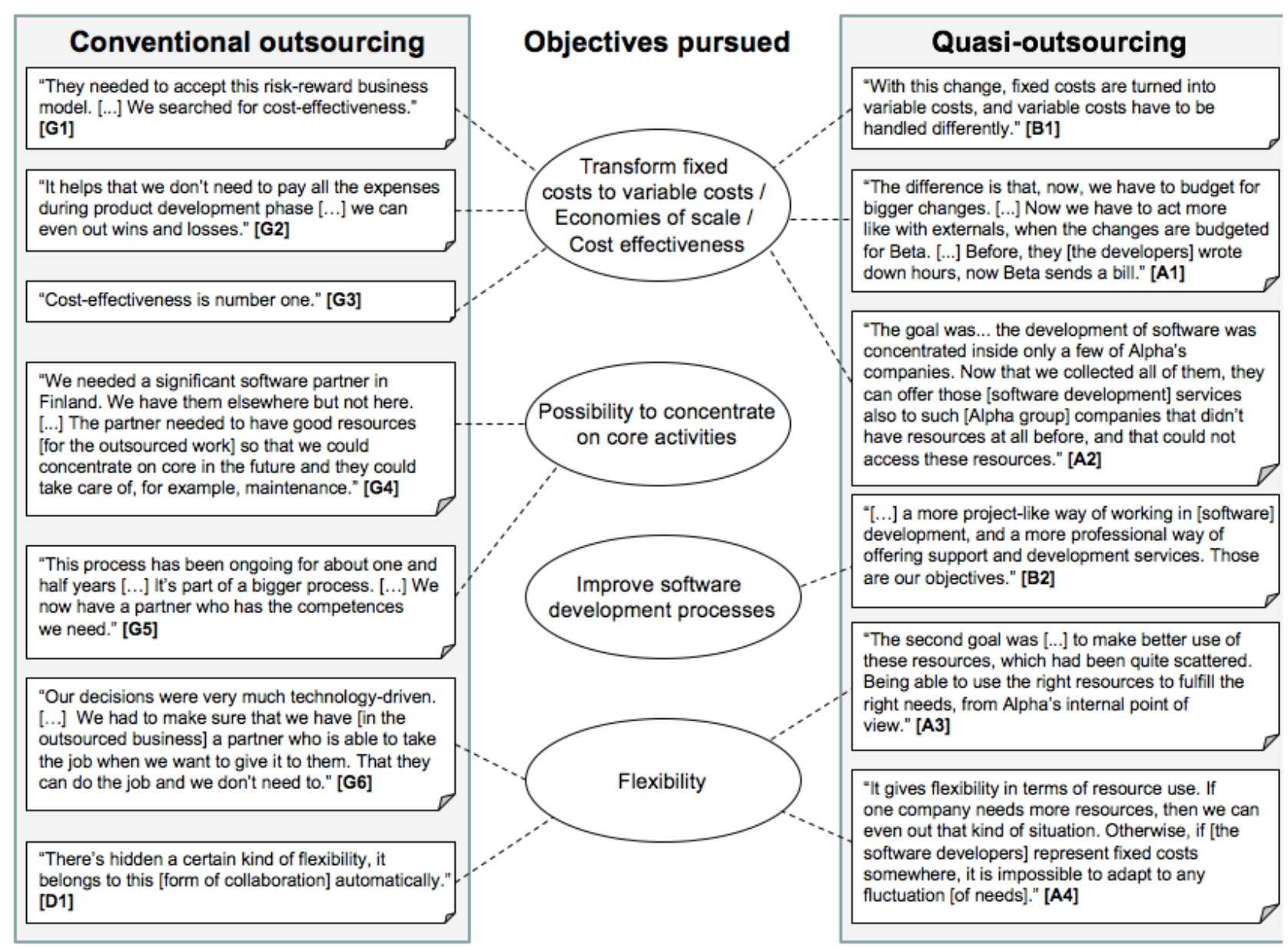

Fig. 1 Gamma's and Alpha's objectives pursued with conventional IS outsourcing and quasi-outsourcing, respectively

\section{Success factors that proved to be less challenging in quasi-outsourcing}

When comparing the success factors we identified as important when establishing collaboration in quasi-outsourcing (case Alpha - Beta) with those in conventional IS outsourcing (case Gamma Delta), we identified several differences between those two types of outsourcing. Next, we present the factors that proved to be less challenging in quasi-outsourcing than in conventional outsourcing. Some of these factors have already been identified in previous research to be common in conventional outsourcing (see Fig. 2) while others have not (Fig. 3).

The service provider evaluation process (see Fig. 2) was very complex in conventional outsourcing, as Gamma had to evaluate and choose among a number of possible service providers to take care of the outsourced activities, first making a short list of candidates and then negotiating separately with 
each candidate [G7, G9]. During the negotiations, the importance of two selection criteria was noticed, namely cultural fit [G8] and trust between the parties. Gamma was looking for a partner that would fit Gamma's organizational culture [G8, G9], and fulfilment of this criterion also created a certain amount of trust in the future collaboration [G10]. When cultural fit and trust existed (as was the case with the chosen service provider), the negotiation process proved satisfactory for both parties. In quasi-outsourcing, the evaluation of different service providers was unnecessary, as Alpha transferred its internal software development resources to its own already existing spin-off Beta, and cultural fit and trust between Alpha and Beta existed already [A5, A6]. Cultural differences between the client and service provider, as well as lack of trust between the parties, have been observed as risk factors in relationship success (Lacity et al. 2009). Similarly, Schulz et al. (2010) have identified the same corporate culture as one of the reasons why IT shared service centers are competitive in providing services to the internal organization compared to alternatives, such as outsourcing to external party providers, and thus support our finding.

Especially, cultural fit proved to be an interesting factor in the case of quasi-outsourcing and will be discussed further later in this paper.

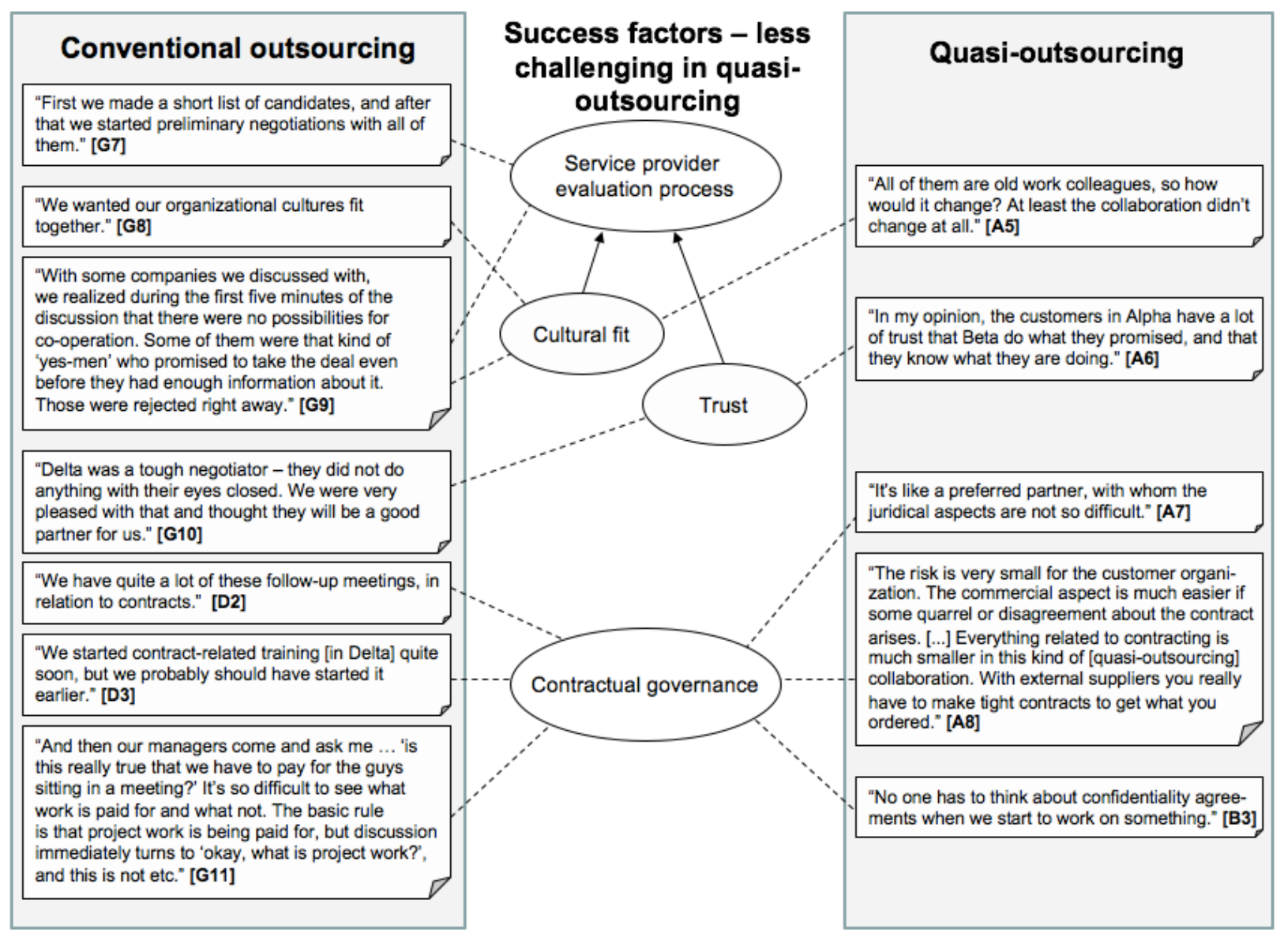

Fig. 2 Success factors that proved to be less challenging in quasi-outsourcing (familiar from previous outsourcing research)

Contractual governance (see Fig. 2) seemed to be less challenging in quasi-outsourcing than in conventional outsourcing. Beta was a 'preferred partner' for Alpha with which making contracts was easier than it would have been with an external provider [A7, A8], and Alpha and Beta did not use confidentiality agreements [B3]. In conventional outsourcing, in contrast, confidentiality was an important issue as Delta had other customers in the same industry. In addition, contracts needed to 
define clearly what was being paid for and what was not [G11]. Both Gamma and Delta employees needed training for that, as well as for being able to take part in the project contract negotiations and project contract follow-up meetings [D2, D3].

Previous research has identified contracts as formal and trust as informal safeguards of opportunism (Barthélemy and Geyer 2005). Based on our findings, we argue that, in quasi-outsourcing, a higher level of trust between the partners results in less complicated contractual governance than in conventional outsourcing (see [A8], Fig. 2). However, other factors apart from trust, e.g. whether the software provider solely serves the parent company or whether the provider also services external customers, influence the level of contractual governance between quasi-outsourcing partners, too.

The group of information technology requirements (see Fig. 3), i.e. practical information technology arrangements needed for the outsourced work, represent factors that have not commonly been addressed as outsourcing success factors in previous research (except in Kinnula and Juntunen 2005). Information technology requirements represented a much bigger challenge in conventional outsourcing than in quasi-outsourcing collaboration. User identification caused many practical difficulties when e-mail addresses and user identifications for PCs and more than 200 applications needed to be checked and possibly changed [G12, D4]. A new physical infrastructure in the form of a project network needed to be created [G13, G14, G16], and software licenses required renegotiating for use in the collaboration environment [G15].

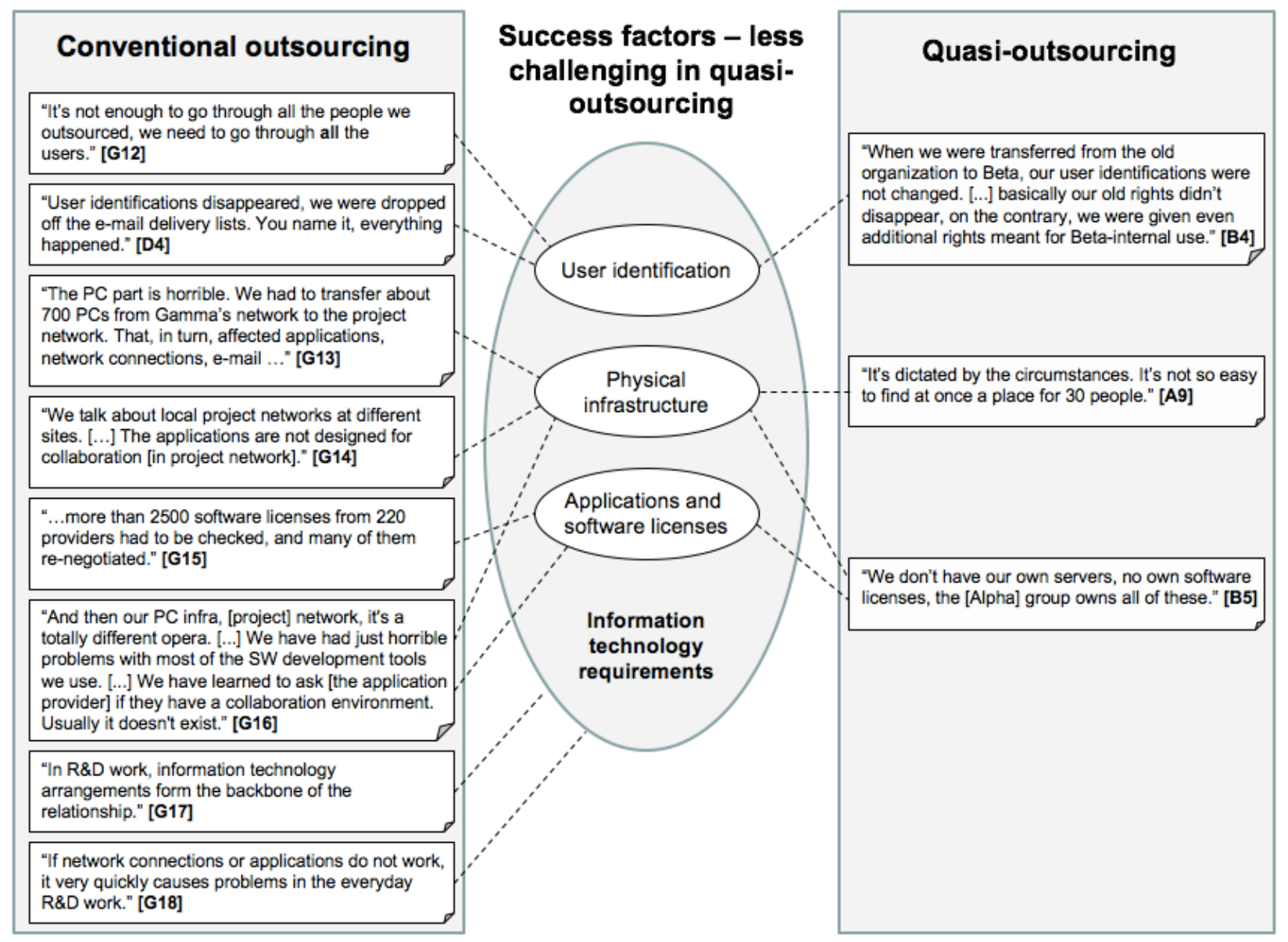

Fig. 3 Success factors that proved to be less challenging in quasi-outsourcing (newly identified) 
In quasi-outsourcing collaboration, for more than half a year after the official transfer of the software developers from Alpha to Beta, the developers stayed in their previous departments [A9], and later on, Beta employees had their offices at Alpha's main site. The transferred employees kept their previous user accounts and privileges [B4]. Beta did not own any software licenses, and used Alpha's IS infrastructure [B5].

Riemer et al. (2009) argue that eCollaboration systems, which enable communication, coordination and collaboration between people in processes between organizations, play an important role in external collaboration including outsourcing. Our study confirms this, and shows that this is even more true in conventional IS than quasi-outsourcing. Bharadwaj et al.'s (2010) study did not prove that the service provider's information technology management competence has an effect on the success of a business process outsourcing relationship. In contrast, our study showed that practical information technology arrangements formed the backbone of the relationship [G17, G18], and thus the service provider's information technology management competence is important. This difference in the findings might be explained by the fact that in our study software development work demands an integrated development environment where the same applications are used in both companies. Bharadwaj et al.'s (2010) study, however, focuses on business process outsourcing where such an environment is not always a necessity. In quasi-outsourcing, the fact that Alpha fully owned Beta made complex information technology arrangements unnecessary as well. However, it is possible that in quasi-outsourcing information technology requirements become more complex if the parent owns the service provider only partially.

Overall, it seems like quasi-outsourcing has a number of significant differences compared to conventional outsourcing, as the service provider evaluation process and information technology requirements could be neglected, contractual issues proved to be much less challenging, and trust and cultural fit already existed by definition.

\section{Success factors that proved more challenging in quasi-outsourcing}

We have previously identified (in Väyrynen and Kinnula 2011) the factors of creating structured interaction and communication processes, defining a clear requirements engineering process, and increasing employees' awareness of the costs of IS services as challenges in quasi-outsourcing. In the present study, we add to these findings by showing that these factors proved more challenging in quasi-outsourcing than conventional outsourcing.

The success factors discussed in this section are interconnected through the factor of cultural fit (Fig. 4). In our quasi-outsourcing case, the most important and most challenging factor for achieving the objective of using software development resources more efficiently was the creation of structured communication and interaction processes, including requirements engineering, inside Beta and between Alpha and Beta. Beta started a project to develop the processes and guidelines for conducting software development projects to define, for example, what kind of meetings should be held and what kind of documents should be used. However, according to Beta's CEO, the project initially failed [B7], partly because the process was developed only by a few persons inside Beta [B8]. Interestingly, the main factor behind the failure, however, seemed to be the existence of cultural fit between the service provider and the customer. Transferring employees from one company to another, as often happens in conventional outsourcing, too, creates some cultural fit between companies as such, as the employees take with them all the knowledge and relationships they have gathered. In quasioutsourcing, cultural fit is even more inherent between the parent company and the spin-off, as was the case in the Alpha-Beta collaboration. The problems of cultural fit in the form of interconnectivity between companies showed especially in Alpha, as the employees had difficulties understanding that 
Beta was a separate company [B6] and were reluctant to change their old ways of working. The situation is not very surprising as quasi-outsourcing did not initially cause major changes in the work environment (see e.g. [B4], Fig. 3). In the Gamma-Delta collaboration, however, cultural fit in the form of both parties being very experienced in doing collaboration, and process improvement work being a normal part of both organizations' culture [D5, D6], proved to be a positive factor in collaboration and helped in developing new interaction processes in a common effort [D7].

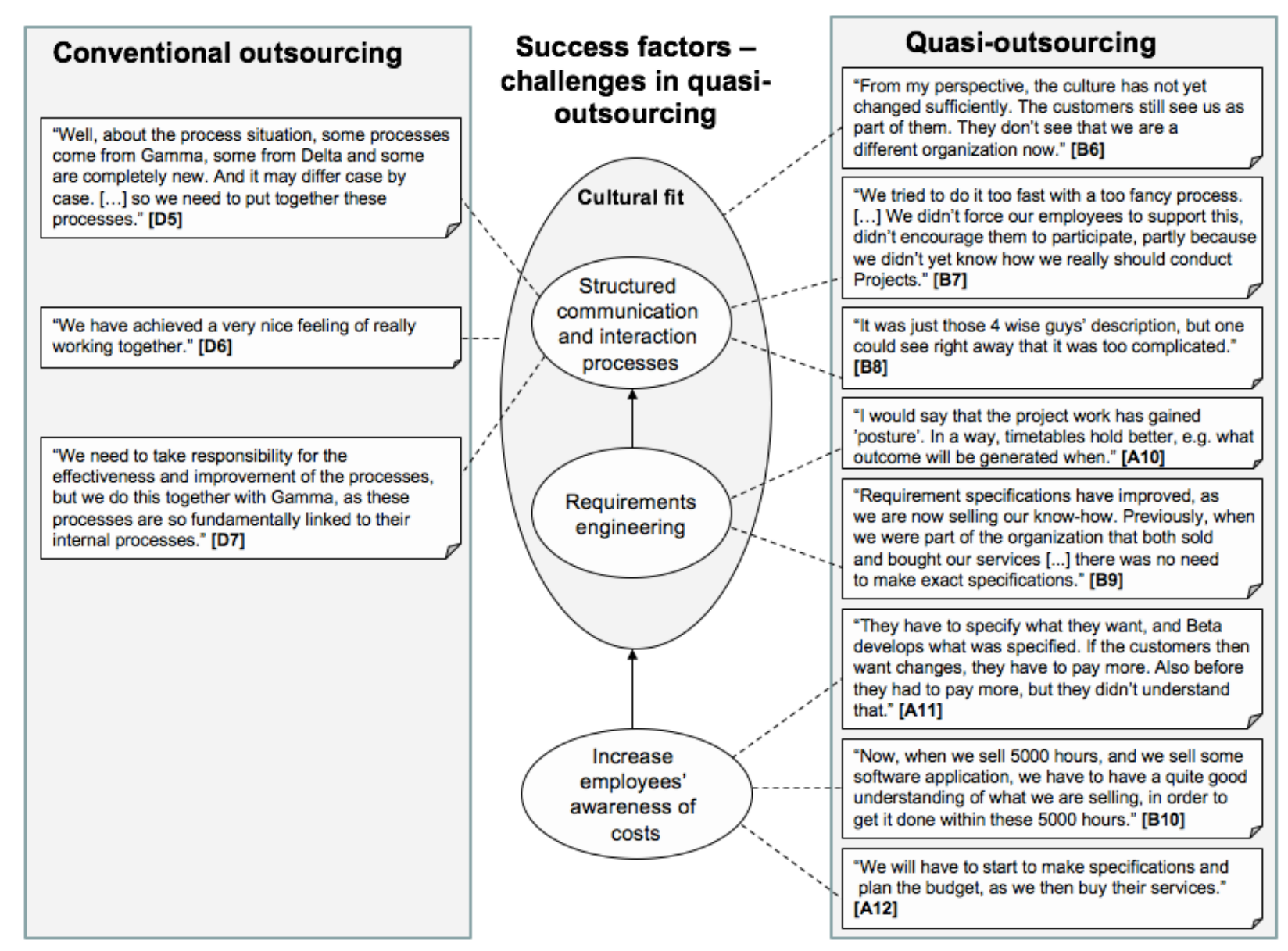

Fig. 4 Success factors that proved to be more challenging in quasi-outsourcing

After the initial project failure, Beta put the project on hold, concentrated on gaining experience in how to conduct software development projects, and restarted the project in 2008, reserving a longer time span than before for the project and planning to define work processes based on the experiences gained during the past 2 years. These efforts showed some effect [A10], improving the requirement engineering process in both Alpha's [A10] and Beta's [B9] opinion. The most essential factor in fulfilling the objective of creating economies of scale in software development, and in succeeding in changing the cultural fit between the parties to allow for the creation of structured communication and interaction processes - including requirements engineering - was to increase employees' awareness of the costs of software development inside Alpha and Beta. Beta conducted many fixedprice projects, added as agreed with Alpha only a small margin to the actual person-hour costs in hour-based pricing, and had to carry the additional costs caused by inaccurate schedule or cost estimations. Therefore, Beta's software developers had to improve their estimation of development schedules and had to create a traceability of costs, i.e. the time spent on developing, maintaining, and supporting software applications [B10]. The customers had a certain budget available for purchasing 
services from Beta [A12], and had to understand that additional development means additional costs [A11].

In the previous research the success factor of understanding and managing all costs - e.g. transaction costs, hidden management costs, and switching costs - has been viewed from a management perspective (Aubert et al. 2005; Ho et al. 2003). However, in order to make quasioutsourcing successful, employees' awareness of the costs involved with IS services has to be raised as well, as identified by Väyrynen and Kinnula (2011) and as further observed above.

At least two reasons could explain why the factors above proved more challenging in quasioutsourcing than in conventional outsourcing. First, Alpha pursued the objective of improving the software development processes with quasi-outsourcing, which partly accounts for the difference in the cases. Second, the outsourcing type may have affected the situation, too, as in quasi-outsourcing there was not such an immediate need to define the contracts and requirements in a detailed level as there was in conventional outsourcing, and thus the pressure to succeed in process improvement was not as high as in conventional outsourcing.

\section{Success factors that show qualitative differences between conventional and quasi-outsourcing}

A number of factors that have already been identified in previous research on success factors of conventional outsourcing proved to be important in the conventional outsourcing and quasioutsourcing cases, but showed substantial differences in their qualitative appearance (Fig. 5).

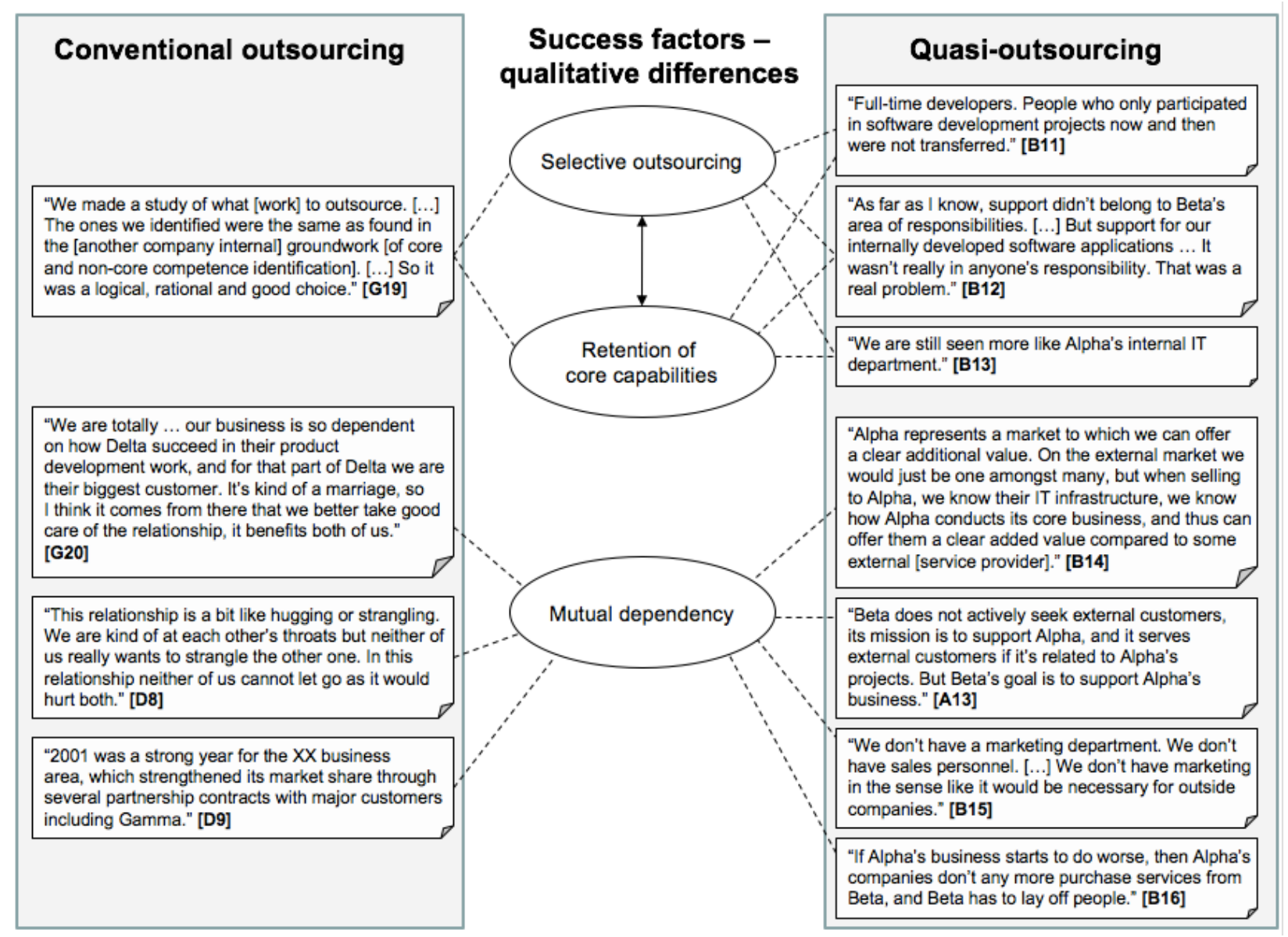

Fig. 5 Success factors showing qualitative differences 
Selective outsourcing showed qualitative differences between conventional outsourcing and quasioutsourcing. In the conventional outsourcing case, one of the objectives was to give Gamma the possibility of concentrating on its core business, and thus, selecting which parts of the R\&D work should be outsourced and which employees should be transferred to the service provider was a rather long and difficult process. It was based on competences needed in Delta to be able to do the outsourced work, as well as competences needed in Gamma to be able to order services in the future [G19]. In quasi-outsourcing, personnel were transferred based on their current work tasks [B11], not based on which part of the IS function they had been responsible for. For example, persons responsible for developing and maintaining the important internal software application ProPI, which was essential for Alpha's core business, were transferred to Beta. However, Beta's responsibility was to offer software development, not software support services, to the Alpha group. As a result, the support function for ProPI was not assigned to anyone, which caused some problems [B12]. As Alpha saw Beta as an internal IT department rather than an external service provider [B13], these problems were not severe and usually solved ad hoc during the companies' everyday collaboration.

Matsuno et al. (2009) proposed that, based on the resource-based view of the firm, quasi-outsourcing is more likely to be chosen if the outsourced activities are a source of competitive advantage, or if IS activity has made a unified contribution to the development of the core business group, but could not support this with their quantitative study. However, based on our study, this was exactly the case in quasi-outsourcing. The qualitative difference in the selective outsourcing success factor was heavily influenced by the ownership structures between the companies. In the quasi-outsourcing case, it would have been easy for Alpha to integrate the software developers back into Alpha, as Alpha fully owned Beta. In conventional outsourcing, however, where the customer does not have ownership of the service provider, competences cannot as easily just be taken back inhouse if the service provider is not able to handle its responsibilities. This was one reason for Gamma's objective of retaining core capabilities in-house. Success of retention of core capabilities was tightly tied to how successful selective outsourcing was and vice versa. Therefore, in our cases, both selective outsourcing and retention of core capabilities seemed to be more important in conventional outsourcing, as in quasioutsourcing the parent company could have taken the personnel and thus the core capabilities back in-house at any time. However, if in quasi-outsourcing the parent company had held only partial ownership of the service provider, selective outsourcing might have closely resembled that of conventional outsourcing.

Even though mutual dependency proved to be important in both types of outsourcing, it differed in quasi-outsourcing and conventional outsourcing (see Fig. 5). Beta was dependent on Alpha, because Alpha represented Beta's key target market to which Beta could offer added value compared to some external service provider [B14]. Alpha was dependent on Beta, too. After the transfer of the software developers, Beta possessed critical expertise concerning the further development, maintenance, and support of Alpha's internal software systems. In addition, the part of Alpha's organization from which most of the software developers had been transferred did not have the freedom to purchase software development, support, and maintenance services from outside service providers. Beta did not try to gain external customers and therefore did not even have its own marketing department [B15]. This strategy corresponded to Alpha's original objectives for Beta [A13] (see also [A2] in Fig. 1), but made Beta dependent on Alpha purchasing Beta's services [B16]. As expected based on previous research findings (e.g. Currie and Willcocks 1998), strong mutual dependency between the parties existed in conventional outsourcing as well [G20], where the parties considered it very difficult to end the relationship [D8]. However, in quasi-outsourcing the service provider was much more dependent on the customer [B16], which fully owned the provider, than in conventional outsourcing, where the service provider had other customers apart from Gamma as shown in Delta's 2001 yearly 
report [D9]. When strong mutual dependency exists, retention of control over outsourcing may also become more difficult for the customer company, but there was not enough data available for either of the cases to prove that.

We have discussed the mutual dependency issue previously (in Väyrynen and Kinnula 2011) in the light of previous research and argue that a quasi-outsourced service provider is less dependent on the parent company if the service provider also serves external customers than if the parent company represents the service provider's whole market. We argue that the parent company's objective of quasi-outsourcing and its degree of ownership have to be considered, too, when evaluating the success of quasi-outsourcing collaboration. As we showed in the present research, the parent company might want to have sole access to the resources of the quasi-outsourced department, and additional service provider customers thus would have a negative impact on quasi-outsourcing success from the parent company's perspective. In addition, Schulz et al. (2010) found that external market activities of IT shared service centers, which can be seen as quasi-outsourced service providers if established as a separate company, in most cases fail, and attracting external customers therefore might not necessarily help the quasi-outsourced company increase its success.

Table 2 Comparison of success factors of conventional IS outsourcing and quasi-outsourcing collaboration

\begin{tabular}{|c|c|}
\hline Finding & Success factor \\
\hline $\begin{array}{l}\text { Success factors which proved more } \\
\text { challenging in quasi-outsourcing than in } \\
\text { conventional outsourcing }\end{array}$ & $\begin{array}{l}\text { Increase employee's awareness of costs } \\
\text { Requirements engineering } \\
\text { Structured communication and interaction processes }\end{array}$ \\
\hline $\begin{array}{l}\text { Success factors which proved less } \\
\text { challenging in quasi-outsourcing than in } \\
\text { conventional outsourcing }\end{array}$ & $\begin{array}{l}\text { Contractual governance } \\
\text { Cultural fit } \\
\text { Trust } \\
\text { Service provider evaluation process } \\
\text { Information technology requirements (user } \\
\text { identification; physical infrastructure; applications } \\
\text { and software licenses) }\end{array}$ \\
\hline $\begin{array}{l}\text { Success factors which proved to have } \\
\text { qualitative differences between } \\
\text { outsourcing types }\end{array}$ & $\begin{array}{l}\text { Mutual dependency } \\
\text { Selective outsourcing } \\
\text { Retention of core capabilities }\end{array}$ \\
\hline $\begin{array}{l}\text { Success factors which proved relevant in } \\
\text { both cases, no difference between cases } \\
\text { observed }\end{array}$ & $\begin{array}{l}\text { Open sharing of information } \\
\text { Quality of service } \\
\text { Top management commitment and support } \\
\text { Understanding and managing all costs (management } \\
\text { viewpoint) }\end{array}$ \\
\hline $\begin{array}{l}\text { Success factors of which there was not } \\
\text { enough data available to make a fair } \\
\text { comparison between cases }\end{array}$ & $\begin{array}{l}\text { Norms } \\
\text { Relationship management process } \\
\text { Retention of control over outsourcing } \\
\text { Values }\end{array}$ \\
\hline
\end{tabular}

To conclude our discussion, we present in Table 2 the same success factors as in Table 1, this time divided on the basis of their relevance and how challenging they proved to be in quasi-outsourcing compared to conventional outsourcing. The success factors that have not previously been listed as 
common factors in conventional outsourcing success (see Table 1) but have proved significant in our study for quasi-outsourcing success are shown in italics.

\section{Conclusions}

This paper has examined data collected in a qualitative, comparative case study of two Finnish companies to find out if and how the factors affecting the success of IS quasi-outsourcing differ from those of conventional IS outsourcing. We found that success factors of IS conventional outsourcing and quasi-outsourcing indeed show significant differences, and these differences have an impact on company decision-making when deciding what kind of outsourcing strategy is pursued. Trust and cultural fit between the service provider and the customer exist in quasi-outsourcing already by definition, while the service provider evaluation process, contractual governance, and especially information technology requirements proved to be less challenging in quasi-outsourcing. The negative influence of cultural fit in quasi-outsourcing can be overcome at least partly by increasing employees' awareness of the costs of IS services. Finally, we identified qualitative differences concerning selective outsourcing, retention of core capabilities, and mutual dependency between these two IS outsourcing types.

This study has some concrete implications for practice related to IS outsourcing, and we hope that our findings help companies that want to outsource all or part of their IS functions to make a more informed decision between conventional IS outsourcing and quasi-outsourcing with full ownership over the quasi-outsourced company. As discussed in this paper, the drivers for outsourcing were in both companies very typical (Lacity et al. 2009). However, the main difference between the companies was Gamma's need to outsource only non-core activities whereas Alpha was more concerned about creating cost-effectiveness through better use of resources through the entire corporation, and that affected the relationship heavily. Thus, when the outsourcing type is selected, company drivers for outsourcing need to be considered carefully to find a collaboration type that fulfills these needs.

Based on the differences in success factors described above, we suggest that, even though trust exists and formal contracts are not always necessary in quasi-outsourcing, contracts are still useful tools for formalizing the relationship and making both parties commit to the task at hand (as stressed e.g. in Kern and Willcocks 2002) and, at the same time, for defining clearly what work is agreed to be included in the contract and how many resources are to be used (and expected to be used) for that work. This can also help with the challenges that may arise from a 'too good' cultural fit between the parties and give the possibility of placing special attention on actively increasing employees' awareness of the costs of software development and maintenance, and on the creation of structured communication and interaction processes including requirements engineering. Service provider evaluation is likely not often performed in quasi-outsourcing cases, but parts of it could still be utilized, at least considering the financial stability of the quasi-outsourced subsidiary, especially in the case that the mother company for some reason ceases to obtain the services of the subsidiary. At the same time, mutual dependency issues should be considered in light of future changes in the relationship between the parent company and the subsidiary. When the quasi-outsourced subsidiary works only for the parent company, information technology requirements are easily fulfilled, and there are very few necessary changes. However, if the subsidiary has external customers, more formal information technology arrangements are likely needed to serve the privacy concerns of those customers. In that case, core capability issues need to be given some consideration as well in order to not sell the company core competences as services to possible competitors. 
Even though this was a single comparative case study conducted in one country, Finland, the results give some indication that there indeed are clear differences between success factors of conventional outsourcing and quasi-outsourcing collaboration, as well as possible explanations for what causes these differences. Based on our research we report in our study differences in eleven success factors of which three proved to be more challenging in quasi-outsourcing than in conventional outsourcing. Our cases were of different size, and Alpha's main business is not in the software industry while Gamma can be considered mainly a software company. It is possible that these differences affected the results, as well as the fact that we did not have enough data available concerning some of the success factors listed in previous literature. Future research could use the results of this study as hypotheses, testing them further in order to establish their validity and to find out if more differences exist. It would also be interesting to investigate under which circumstances and why quasioutsourcing represents an advantage or disadvantage over conventional outsourcing for a company. This study focused on a case where the parent maintained full ownership of the quasi-outsourced company, and future research could study the success factors of quasi-outsourcing collaboration in a partial ownership setting to find out whether our findings are specific to quasi-outsourcing where the parent maintains full ownership. Finally, the success factors of user identification, physical infrastructure, and applications and licenses, which all represent information technology requirements and proved challenging in conventional outsourcing, but are not commonly mentioned in previous IS literature, would be interesting to investigate further to find out how common they are in both conventional and quasi-outsourcing settings.

Acknowledgements. The first author would like to thank the Oulu University Scholarship Foundation, the Tauno Tönning Foundation, the Jenni and Antti Wihuri Foundation, and the ROOSTER - Smart Phone Innovation Cluster project for financial support during the research. Both authors would like to thank the anonymous reviewers and the editors for their valuable comments.

\section{References}

Anthony, R. N., Dearden, J., \& Vancil, R. F. (1972). Key economic variables (pp. 138-143). Irwin: Management Control Systems, Homewood.

Aubert, B. A., Dussault, S., Patry, M., \& Rivard, S. (1999). Managing the risk of IT outsourcing. In: Proceedings of the Thirty-second Annual Hawaii International Conference on System Sciences. IEEE Computer Society.

Aubert, B. A., Patry, M., \& Rivard, S. (2005). A framework for information technology outsourcing risk management. Database for Advances in Information Systems, 36(4), 9-28.

Bahli, B., \& Rivard, S. (2005). Validating measures of information technology outsourcing risk factors. Omega, 33(2), 175-187.

Baldwin, L., Irani, Z., \& Love, P. (2001). Outsourcing information systems: drawing lessons from the banking case study. European Journal of Information Systems, 10(1), 15-24.

Bandyopadhyay, S., \& Pathak, P. (2007). Knowledge sharing and cooperation in outsourcing projects-A game theoretic analysis. Decision Support Systems, 43(2), 349-358.

Barthélemy, J. (2003). The hard and soft sides of IT outsourcing management. European Management Journal, 21(5), 539-548.

Barthélemy, J., \& Geyer, D. (2001). IT outsourcing: evidence from France and Germany. European Management Journal, 19(2), 195-202.

Barthélemy, J., \& Geyer, D. (2005). An empirical investigation of IT outsourcing versus quasioutsourcing in France and Germany. Information \& Management, 42(4), 533-542. 
Bharadwaj, S., Saxena, K. B. C., \& Halemane, M. D. (2010). Building a successful relationship in business process outsourcing: an exploratory study. European Journal of Information Systems, 19 (2), 168-180.

Currie, W., \& Willcocks, L. (1998). Analyzing four types of IT sourcing decisions in the context of scale, client/supplier interdependency and risk mitigation. Information Systems Journal, 8(2), 119143.

Currie, W., Michell, V., \& Abanishe, O. (2008). Knowledge process outsourcing in financial services: the vendor perspective. European Management Journal, 26(2), 94-104.

Dibbern, J., Goles, T., Hirschheim, R.,\&Jayatilaka, B. (2004). Information systems outsourcing: a survey and analysis of the literature. Database of Advances in Information Systems, 35(4), 6-102.

DiRomualdo, A., \& Gurbaxani, V. (1998). Strategic intent for IT outsourcing. Sloan Management Review, 39(4), 67-80.

Earl, M. (1996). The risks of outsourcing IT. Sloan Management Review, 37(3), 26-32.

Eisenhardt, K. M. (1989). Building theories from case study research. Academy of Management Review, 14(4), 532-550.

Golafshani, N. (2003). Understanding reliability and validity in qualitative research. The Qualitative Report, 8(3), 597-606.

Grover, V., Cheon, M.,\&Teng, T. (1996). The effect of service quality and partnership on the outsourcing of information systems functions. Journal of Management Information Systems, 12(4), 89-116.

Ho, V., Ang, S., \& Straub, D. (2003). When subordinates become IT contractors: persistent managerial expectations in IT outsourcing. Information Systems Research, 14(1), 66-125.

Ito, K. (1995). Japanese spinoffs: unexplored survival strategies. Strategic Management Journal, 16(6), 431-446.

Kern, T., \& Blois, K. (2002). Norm development in outsourcing relationships. Journal of Information Technology, 17(1), 33-42.

Kern, T., \& Willcocks, L. (2000). Exploring information technology outsourcing relationships: theory and practice. Journal of Strategic Information Systems, 9(4), 321-350.

Kern, T., \& Willcocks, L. (2002). Contract, control, and "presentation" in IT outsourcing: research in thirteen UK organizations. In F. Tann (Ed.), Advanced topics of global information management (pp. 227-249). London: Idea Group.

Kinnula, M., \& Juntunen, S. (2005). A case study of success factors in outsourcing partnership formation and management. In: Proceedings of IMP conference. Rotterdam, Netherlands, September 2005.

Lacity,M., \&Willcocks, L. (1998). An empirical investigation of information technology sourcing practices: lessons from experience. MIS Quarterly, 22(3), 363-408.

Lacity, M., Hirschheim, R., \& Willcocks, L. (1994). Realizing outsourcing expectations. Information Systems Management, 11(4), 7-18.

Lacity, M., Willcocks, L., \& Feeny, D. (1996). The value of selective IT sourcing. Sloan Management Review, 37(3), 13-25.

Lacity, M., Khan, S., \& Willcocks, L. (2009). A review of the IT outsourcing literature: insights for practice. Journal of Strategic Information Systems, 18(3), 130-146.

Lee, A., \& Baskerville, R. (2003). Generalizing generalizability in information systems research. Information Systems Research, 14 (3), 221-243.

Lee, J.-N., \& Kim, Y.-G. (1999). Effect of partnership quality on IS outsourcing success: conceptual framework and empirical validation. Journal of Management Information Systems, 15(4), 26-61. 
Matsuno, S., Ito, T., Uchida, Y., \& Tagawa, S. (2009). An empirical investigation of IS outsourcing in Japan. International Journal of Education and Information Technologies, 3(2), 105-114.

Pettigrew, A. (1997). What is a Processual Analysis? Scandinavian Journal of Management, 13(4), 337-348.

Riemer, K., Steinfield, C., \& Vogel, D. (2009). eCollaboration: on the nature and emergence of communication and collaboration technologies. Electronic Markets, 19(4), 181-188.

Romano, N., Pick, J. B., \& Roztocki, N. (2010). A motivational model for technology-supported cross-organizational and cross-border collaboration. European Journal of Information Systems, 19(2), 117-133.

Sabherwal, R. (1999). The role of trust in outsourced IS development projects. Communications of the ACM, 42(2), 80-86.

Schulz, V., Herz, T. P., Rothenberg, M. A., \& Brenner, W. (2010). IT shared service center and external market activities. In AMCIS 2010 Proceedings. Paper 532.

Smith, H., \& McKeen, J. (2004). Developments in practice XIV: IT outsourcing-how far can you go? Communications of the AIS, 13(1), 508-520.

Väyrynen, K. E., \& Kinnula, M. (2011). Investigating the differences between success factors of conventional IS outsourcing and quasi-outsourcing. In: Proceedings of the Forty-fourth Annual Hawaii International Conference on System Sciences. IEEE Computer Society.

Venkatraman, N. (1997). Beyond outsourcing: Managing IT resources as a value center. Sloan Management Review, 38(3), 51-64.

Willcocks, L., \& Kern, T. (1998). IT outsourcing as strategic partnering: the case of the UK Inland Revenue. European Journal of Information Systems, 7(1), 29-45.

Williamson, O. (1985). The economic institutions of capitalism. New York: Free Press.

Yin, R. K. (2003). Case study research. Thousand Oaks: Sage. 